\title{
Aiming for the Stars: Vision and Aspirations for the Journal of Wound Management and Research
}

\author{
Hyonsurk Kim (10) \\ Department of Plastic and Reconstructive Surgery, Dankook University Hospital, Cheonan, Korea
}

First published in May 2017, the Journal of Wound Management and Research (JWMR) succeeds the Journal of Korean Wound Management Society and the Journal of the Korean Wound Care Society as the official journal of the Korean Wound Management Society (KWMS). The previously local, Korean-language journal was revamped for enhanced academic robustness with a new name and cover design, an online manuscript submission system, and began accepting the majority of its articles in English language rather than Korean, and also made full texts of all articles available online (open access) to embrace authors and readers from around the world.

About a year after JWMR was launched, I was appointed editor-in-chief of the journal. As I was neither a seasoned editor nor an experienced publisher, the appointment was rather unexpected, not only for myself but probably for many of our contributing authors, readers and editorial board members as well. Looking back on the past 21 months, I am reminded of Winston Churchill's speech to the British House of Commons on May 13, 1940, in which he claimed to have "nothing to offer but blood, toil, tears, and sweat." Comparing JWMR's first 2 years to the British endeavor against Nazi Germany would of course be self-aggrandizing, but I would like to reflect that the toil and sweat of the editorial board and publication staff have produced some noteworthy results.

During these past 2 years, JWMR has been either admitted to or registered with the Korean Federation of Science and Technology Societies (KOFST), the Korean Association of Medical Journal Editors (KAMJE), the Korean Council of Science Editors, and the National Research Foundation (NRF) of Korea. The journal's copyright has been registered at Korea Journal Copyright Information of the National Library of Korea. JWMR has also successfully obtained the 2019 KOFST grant for journal publications funded by the Korean government, and has used this funding to, among other projects and expenses, sign contracts with professional manuscript editing and English proofreading resources. The resulting addition of a manuscript editor and English editor has greatly improved the consistency and quality of JWMR's publication style and English prose, while lessening the burden of peer reviewers.

In accordance with the global trend for stricter ethical standards in academic research and publication, the journal's Instructions for Authors and Research and Publication Ethics have been intensively revised. The peer-review process has also been overhauled, stepping up screening for plagiarism by adopting Crossref Similarity Check, and providing specific guidelines for our pool of peer reviewers including
Editorial

Received: February 17, 2020

Accepted: February 18, 2020

Corresponding author:
Hyonsurk Kim, M.D.

Department of Plastic and Reconstructive Surgery, Dankook University Hospital, 201 Manghyang-ro, Dongnam-gu, Cheonan 31116, Korea

Tel: +82-41-550-6285

Fax: +82-41-556-0524

E-mail: pshyon@dankook.ac.kr

This is an Open Access article distributed under the terms of the Creative Commons Attribution Non-Commercial License (https://creativecommons.org/licenses/by-nc/4.0/) which permits unrestricted non-commercial use, distribution, and reproduction in any medium, provided the original work is properly cited.

(c) 2020 Korean Wound Management Society 
professionals from the United Kingdom, Japan, Thailand, and Romania. Two independent statistics editors specializing in biomedical statistics have also been appointed to review the statistical analyses in submitted manuscripts. Together, these changes have resulted in a marked decrease in the journal's acceptance rate and a steep increase in the number of revisions required before acceptance. While this may, regretfully, seem troublesome to some authors, I believe the majority will understand that these efforts are to ensure the quality of JWMR's content.

The most reliable indices of the quality of a journal's content would be its citations and indexations in scientific databases. Citations of articles published in JWMR are steadily increasing, and the journal has a favorable Science Citation Index Expanded (SCIE) impact factor, notwithstanding the fact that it is less than 3 years old and has not been indexed in any international scientific database (excluding Google Scholar and Crossref). One year after JWMR was admitted to KAMJE, the journal applied for KAMJE's New Journal Evaluation and qualified, earning its registration on the KoreaMed indexing database. Beginning this year (2 years after being admitted to the NRF), JWMR will publish triannually, and will apply for evaluation as an NRF Registered Journal Nominee. This will no doubt require more toil, tears and sweat from the editorial board and staff, but successful registration as an NRF Registered Journal Nominee will prompt more academics to publish in the journal, further enhancing its quality. Once this milestone is attained, JWMR will focus on transforming itself into a truly international publication, beginning with publishing exclusively in English, with the goal of indexation on the Emerging Sources Citation Index (ESCI), PubMed Central, and Scopus.

Of course, these aspirations are by no means easy to accomplish, but aiming for the stars will always get us further than only committing to quick wins. In recent years KWMS has earned significant recognition, both domestically and internationally, through its academic activities. It is only fitting that the official journal of KWMS should strive to earn similar recognition. As editor-in-chief, I am grateful to the peer reviewers and editorial board members who have volunteered their valuable time and talent to help strengthen JWMR, and at the same time ask for their continued efforts, and of course for the much-appreciated contribution of clinicians and researchers in the form of submitted manuscripts, in fulfilling the vision of our journal.

\section{Conflict of interest}

HK is editor-in-chief of the Journal of Wound Management and Research. No other potential conflict of interest relevant to this article was reported.

\section{ORCID iD}

Hyonsurk Kim https://orcid.org/0000-0001-6576-8035 